\title{
Experimental Research on Acoustic Emission Characteristics and Felicity Effects during Coal Fatigue Failure under Cyclic Loading
}

\author{
Yongjie Yang $\mathbb{D}^{1,2}$ and Luyi Xing $\mathbb{D}^{1,2,3}$ \\ ${ }^{1}$ College of Energy and Mining Engineering, Shandong University of Science and Technology, Qingdao, Shandong 266590, China \\ ${ }^{2}$ State Key Laboratory of Mining Disaster Prevention and Control Co-founded by Shandong Province and the Ministry of \\ Science and Technology, Shandong University of Science and Technology, Qingdao, Shandong 266590, China \\ ${ }^{3}$ Shandong Jianzhu University, Jinan, Shandong 250101, China \\ Correspondence should be addressed to Luyi Xing; 981445815@qq.com
}

Received 24 April 2020; Revised 30 June 2020; Accepted 15 July 2020; Published 27 August 2020

Academic Editor: Zbyšek Pavlík

Copyright (c) 2020 Yongjie Yang and Luyi Xing. This is an open access article distributed under the Creative Commons Attribution License, which permits unrestricted use, distribution, and reproduction in any medium, provided the original work is properly cited.

\begin{abstract}
In order to study the acoustic emission characteristics and Felicity effect in the process of coal fatigue failure and reveal the internal relationship between the fatigue damage evolution law and the acoustic emission activity, with the help of MTS815.02 electrohydraulic servo rock mechanics test system and PCI-2 acoustic emission detection and analysis system, a triaxial cycling loading acoustic emission test was carried out on the coal samples. The results show that the higher the upper limit stress is, the more obvious the degree of fatigue damage will be caused by coal samples. At the same time, the more active acoustic emission signal will appear. The coal samples under linear loading are on the initial damage state, and slight fatigue, moderate fatigue, deep fatigue, and ultimate fatigue failure under cyclic loading. The acoustic emission shows the "L-" type development evolution law in any previous stress level range, while at the last stress level, it shows the obvious "U-" type development evolution law. The higher the frequency of the cyclic loading is, the higher the rate of initiation and expansion of the microcrack will be, while the more obvious acoustic emission phenomenon will appear. Furthermore, the ringing counting rate is basically the same as that of the energy counting rate. Under triaxial cyclic loading, a shear failure mode that extends along different directions of fracture surface will be presented. The acoustic emission in the range of different stress levels shows a different degree of Felicity effect. In contrast, it is more reasonable to use the principal stress difference as a parameter to study the Felicity effect of coal under cyclic loading.
\end{abstract}

\section{Introduction}

Damage failure mechanisms and mechanical properties of rocks and coal under monotonic loading (uniaxial and conventional triaxial compression) have been extensively studied [1-6]. Pervasive microcracking occurs in the interior of rocks and coal under external loading, which ultimately leads to fatigue and failure. The compaction and closure of primary cracks is known to occur simultaneously with the gradual initiation, propagation, cracking, and penetration of new cracks. This process is accompanied by the release of strain energy in the form of transient elastic waves or stress waves called acoustic emission (AE), which is frequently called "stress wave emission" [7-9].
Acoustic emission techniques have been widely used in the field of rock mechanics and mine engineering [10-17] as a dynamic nondestructive test for measuring the crack propagation characteristics of brittle materials such as rock, coal, and concrete. However, research and application of coal fatigue damage tests under cyclic loading remain scarce. Liu et al. [18] studied the damage evolution and acoustic emission characteristics of coal under uniaxial compression. Acoustic emission information is believed to be closely related to the formation, expansion, and penetration of primary fractures in coal and can provide insight into its deformation and damage evolution behavior. Ji and $\mathrm{Lu}$ [19] performed acoustic emission tests on granite under different confining pressures, obtained the mechanical parameters of 
the entire rock fracture process, and analyzed the acoustic emission characteristics of granite from triaxial compression tests. Song et al. [20] carried out uniaxial compression tests on red sandstone. The evolution of rock deformation in the field during loading was observed using the digital speckle correlation method and AE signals were collected using an acoustic emission detection system. They also systematically studied the corresponding acoustic emission characteristics, extension, dislocation, and overall evolution of the localized deformation zone during deformation in the field. Shahidan et al. [14] studied the acoustic emission behavior of reinforced concrete beams under cyclic loading, classified tensile-shear cracks on the basis of the acoustic emission amplitude, rise time, average frequency, and signal strength, and determined the damage level and crack propagation law. Zou et al. [21] systematically studied the damage evolution characteristics of raw coal under uniaxial and triaxial cyclic loading using acoustic emission technology. They concluded that acoustic emission phenomena during the initial stage of loading is more significant under graded cyclic loading conditions and that raw coal exhibits different damage evolution characteristics at different cyclic stages. Xiao et al. [22] studied the law of energy conversion and acoustic emission characteristics of coal under cyclic loading. They proposed that coal instability can be predicted by the abrupt rise of AE energy and abrupt drop of AE amplitude. Zhang et al. [23] observed accelerated energy release during loading, which is closely related to the occurrence of larger cracks in rocks and can be used as a precursor of rock macrofailure through analysis of acoustic emission test data of three types of rocks. Kong et al. [24-26] determined the relationship between acoustic emission parameters and stress-strain of coal samples under uniaxial compression and derived qualitative and quantitative expressions of coal damage variables. Although many studies have contributed important achievements in understanding the acoustic emission characteristics of rock deformation and failure, these features during different loading paths remain scarcely reported, especially for the fatigue damage failure evolution of coal under cyclic loading. A more comprehensive and systematic study of the acoustic emission characteristics of coal fatigue damage failure is therefore required.

We performed acoustic emission tests on coal samples under triaxial cyclic loading using a MTS815.02 electrohydraulic servo rock mechanics test system and PCI-2 acoustic emission detection analysis system. We use the results to better understand the characteristics of acoustic emission and the Felicity effect under different stress levels and cyclic loading frequencies during coal fatigue failure.

\section{Materials and Methods}

2.1. Starting Material and Test Equipment. In order to minimize dispersion of the test results owing to individual differences of natural coal samples and avoid the obvious difference of stress history and stress state caused by different horizons and depths as far as possible, the slotting method was adopted to carve coal blocks in relatively complete coal bodies with undeveloped joints. Coal samples were extracted using a drill coring machine and processed into cylindrical specimens with approximate dimensions of $100 \mathrm{~mm}$ in height and $50 \mathrm{~mm}$ in diameter. The parallelism of the two ends was controlled within $0.01 \mathrm{~mm}$. After being formed, a natural drying state was maintained and a fresh film was used. The sealing is shown in Figure 1(a). In order to reduce the influence of the discreteness of the coal samples on the test results, the acoustic velocity test was performed on all the samples that were processed. Finally, the samples with the greater dispersion of the acoustic velocity were removed, and the samples with the most similar acoustic velocity were used for testing and numbered sequentially [16].

Conventional triaxial cyclic loading tests were performed using an MTS815.02 electrohydraulic servo rock mechanics test system developed by American Mechanical Testing and Simulation (MTS) Corporation, as shown in Figure 1(b). The maximum axial load of the equipment is $1700 \mathrm{kN}$, the maximum confining pressure is $50 \mathrm{MPa}$, and the maximum pore pressure is $50 \mathrm{MPa}$. The system provides a highly accurate and stable performance, can obtain high- and lowspeed data, and allows uniaxial or triaxial compression tests, cyclic loading tests, permeability tests, and creep tests using force, displacement, axial strain, transverse strain, and other control modes. We used a six-channel PCI-2 acoustic emission detection and analysis system produced by the American Physical Acoustic Corporation, as shown in Figure 1(c). The system uses a PCI-2 board (i.e., contains only two channels), which effectively reduces acquisition noise and ensures the authenticity of AE signals. Because the PCI-2 acoustic emission detection and analysis system is digital, it offers ultra-fast processing speed, low noise, low threshold, and reliable stability.

2.2. Acoustic Emission Test Method. As a matter of fact, the $\mathrm{AE}$ detector at the previous triaxial compression acoustic emission tests was usually placed outside the triaxial chamber or on the coal sample, as shown in Figures 2 and 3. In this way, it is very difficult to obtain the comprehensive and reliable acoustic emission detection signals [17].

In order to solve the problem that the AE detector could not withstand the pressure of the hydraulic oil in the triaxial chamber, the test head that can seal the AE detector inside the triaxial chamber was developed [17], as shown in Figure 4 . Therefore, the triaxial cyclic loading acoustic emission test method for coal samples can be optimized, which is convenient to use a more reasonable acoustic emission test method to carry out the acoustic emission test of different loading paths, especially cyclic loading, under the triaxial condition.

As shown in Figure 5, taking a confining pressure $3 \mathrm{MPa}$ as an example, the left and right sides represent the acoustic emission parameter curves with AE detector outside and inside the triaxial chamber, respectively. We can find that more accurate acoustic emission information can be detected when the AE detector is inside the triaxial chamber. The maximum ringing count of coal sample is 8,326 with $\mathrm{AE}$ detector inside the triaxial chamber, while 5,230 outside the 


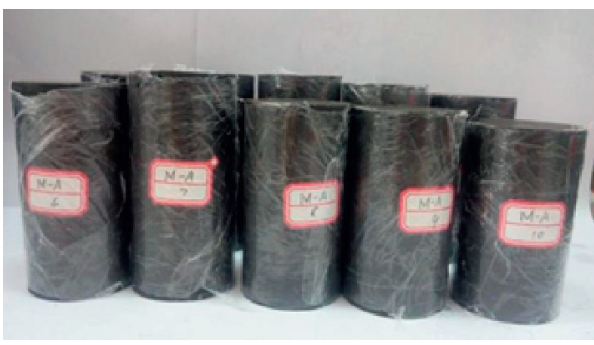

(a)

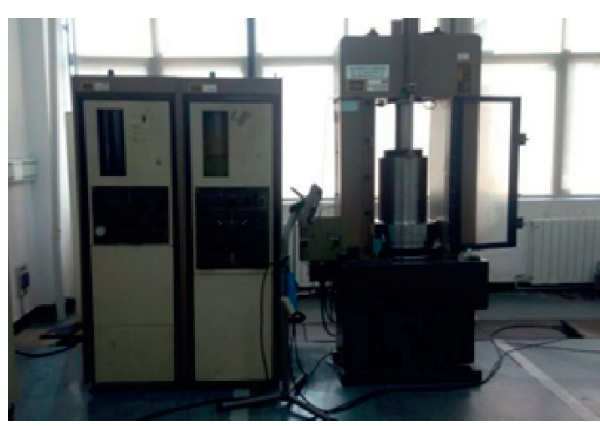

(b)

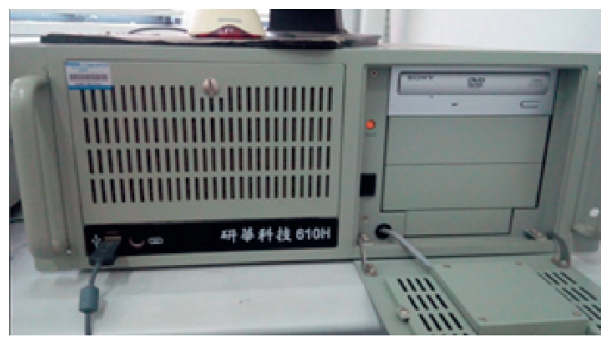

(c)

FIGURE 1: Standard coal samples and test equipment. (a) Standard coal samples, (b) MTS815.02 electrohydraulic servo rock mechanics test system, and (c) PCI-2 acoustic emission detection and analysis system.

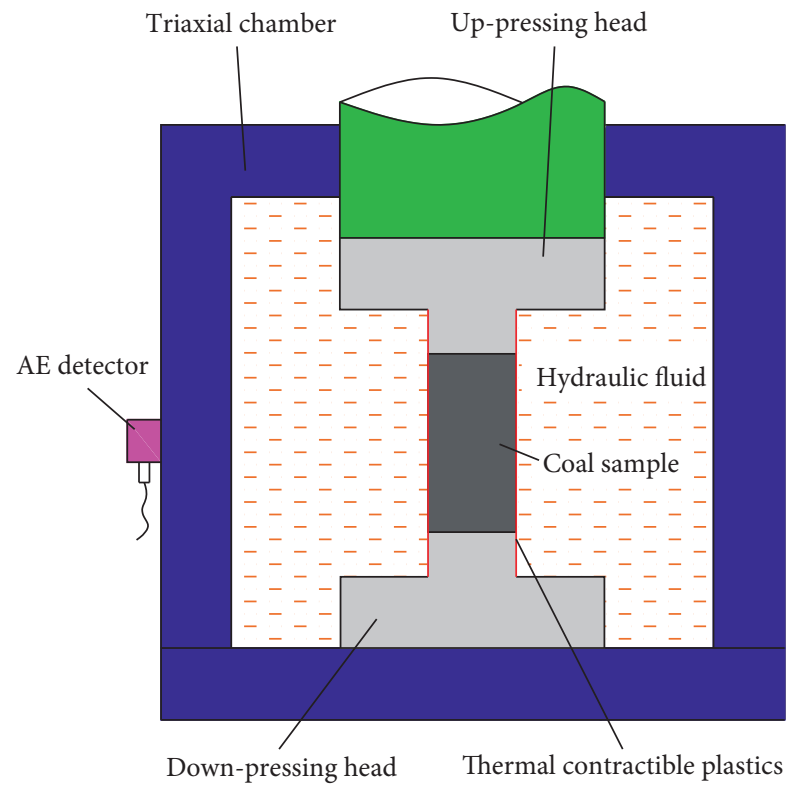

FIgURE 2: AE detector placed outside the triaxial chamber.

triaxial chamber. The maximum AE energy is $30,036 \mathrm{mV}$ with $\mathrm{AE}$ detector inside the triaxial chamber, while being $24,198 \mathrm{mV}$ outside the triaxial chamber. The maximum number of ringing counts with $\mathrm{AE}$ detector inside the triaxial chamber is $59.2 \%$ higher than that with $\mathrm{AE}$ detector outside the triaxial chamber, and the energy is $24.1 \%$ higher than that outside the triaxial chamber.

Through this method, it is easy to find that the triaxial chamber fluid will not have any effect on the performance of the AE signals, and the accuracy of experimental results will be improved effectively.

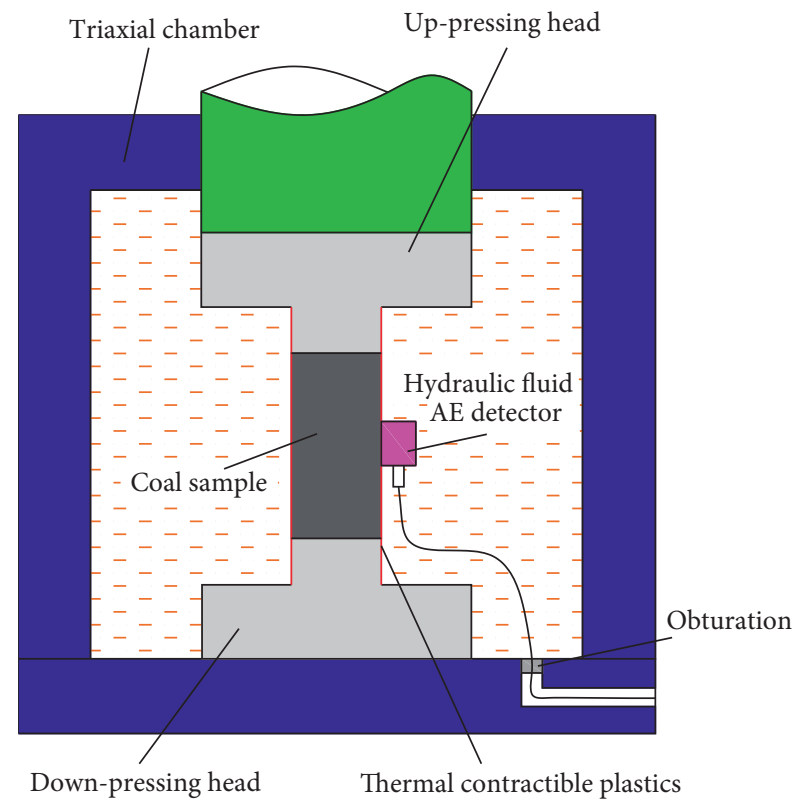

Figure 3: AE detector placed on the coal sample.

2.3. Experimental Procedure. To compare and analyze the acoustic emission characteristics of coal samples under different stress levels and cyclic loading frequencies, the control variables of the servo test system were controlled by stress, and the loading waveforms were uniformly selected as sinusoidal waves (Figure 6). During testing, cyclic fatigue tests were performed on one hundred standard coal samples under two loading frequencies of 0.25 and $0.5 \mathrm{~Hz}$, fixed lower limit stress (30\% of the average compressive strength of the conventional triaxial), and variable upper limit stress. 


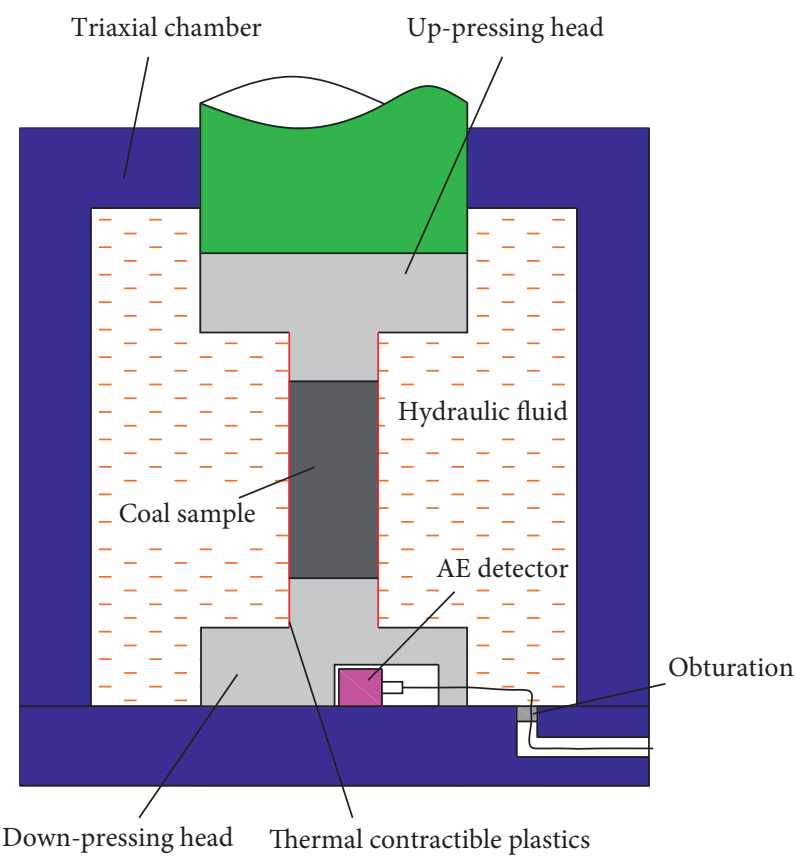

Figure 4: AE detector placed in a test head.
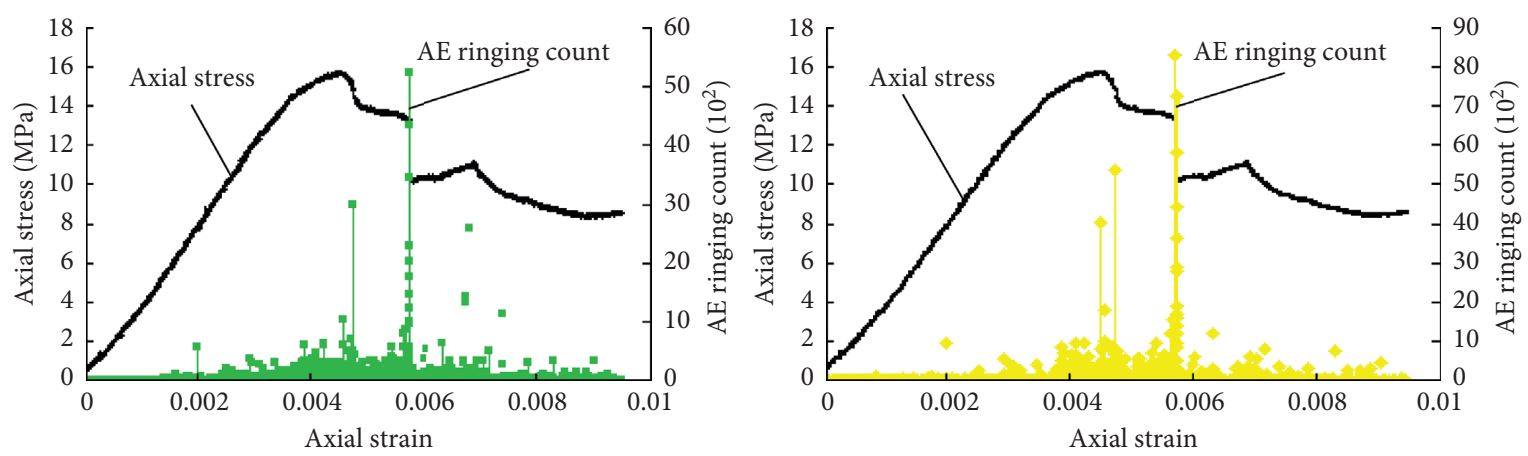

(a)
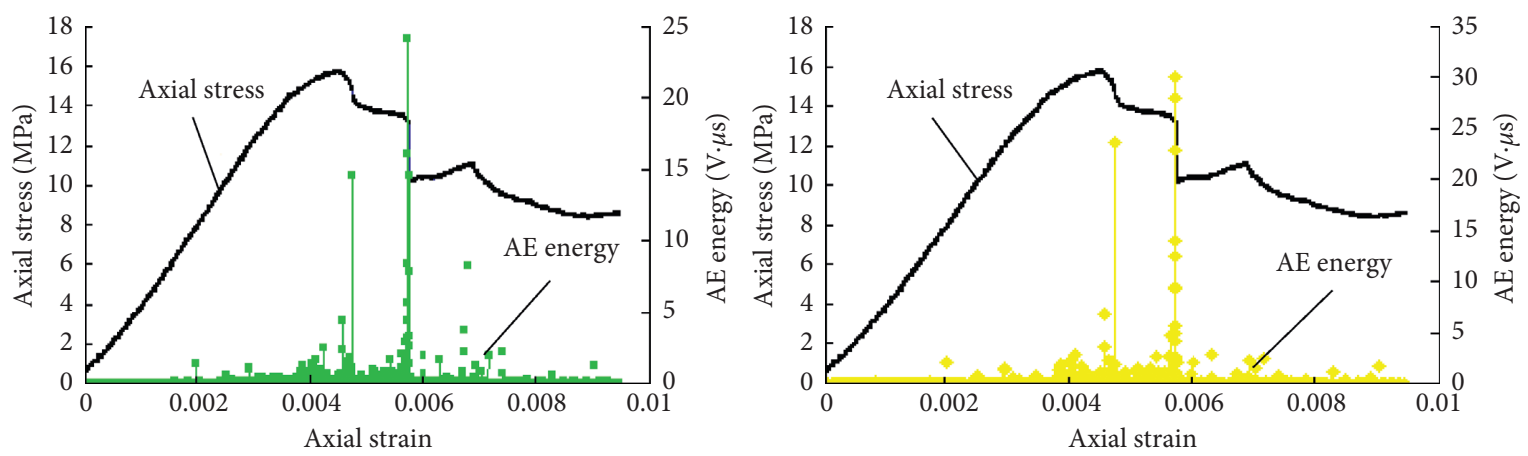

(b)

Figure 5: Acoustic emission parameter curves of coal sample. (a) AE ringing count and (b) AE energy.

The loading of the coal samples was increased to the next stress level until fatigue failure occurred. In order to obtain the average compressive strength, conventional triaxial compression tests were carried out on samples from the same coal block. Since the acoustic emission characteristics of coal samples under the same loading frequency are roughly the same, only two coal samples are used for comparative analysis on each loading frequency. The mechanical parameters of each coal sample are listed in Table 1. Because the test results under the same conditions are essentially the same, only two cyclic loading tests are selected for further analysis in this paper. The threshold value, gain 


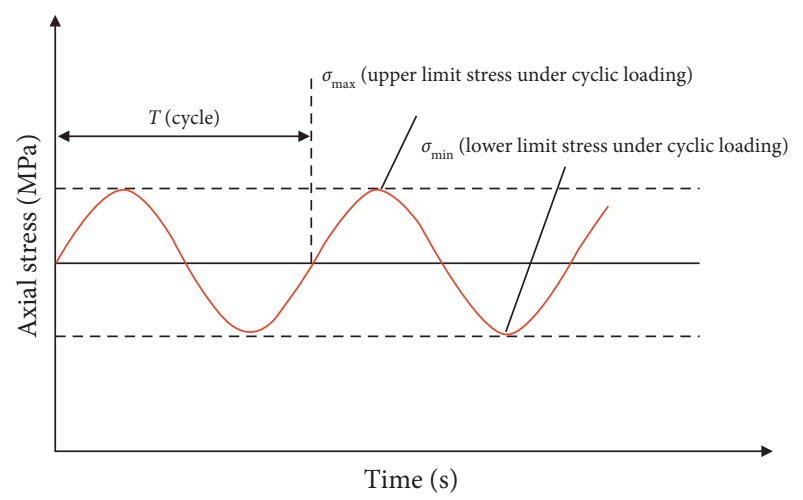

Figure 6: Diagram of cyclic loading wave.

multiple, and data acquisition parameters of the acoustic emission tests are determined according to pre-test analyses. The acoustic emission characterization parameters can be selected as ringing counting rate, impact counting rate, energy counting rate, amplitude, and others, as discussed later.

\section{Acoustic Emission Characteristics of Coal under Cyclic Loading}

3.1. Effect of Stress Level on Acoustic Emission Characteristics. The mechanical energy absorbed by coal is transformed into other kinds (e.g., acoustic, electromagnetic, and thermal) under an external load, and most of the strain energy is used for deformation. The stress-strain curve of coal under cyclic loading consists of a series of plastic hysteresis loops, and the area of each plastic hysteresis loop represents the energy consumed by each cycle.

$$
\Delta E=\oint \Delta \sigma \mathrm{d} \varepsilon
$$

The deformation of coal sample $(\varepsilon)$ in each cycle includes elastic deformation $\left(\varepsilon_{\mathrm{e}}\right)$ and plastic deformation $\left(\varepsilon_{\mathrm{p}}\right)$.

$$
\Delta E=\oint \Delta \sigma \mathrm{d} \varepsilon_{\mathrm{e}}+\oint \Delta \sigma \mathrm{d} \varepsilon_{\mathrm{p}}
$$

In a closed hysteresis loop, the elastic strain energy can be regarded as zero, so the energy consumption of each cycle is almost entirely caused by plastic strain.

$$
\Delta E=\oint \Delta \sigma \mathrm{d} \varepsilon_{\mathrm{p}}
$$

The stress in each cycle can be approximated by a power function.

$$
\Delta \sigma=k\left(\Delta \varepsilon_{p}\right)^{n}
$$

Equations (3) and (4) are simultaneously available.

$$
\Delta E=\frac{k}{n+1}\left(\Delta \varepsilon_{\mathrm{p}}\right)^{n+1}=\frac{\Delta \varepsilon_{\mathrm{p}}}{n+1} k\left(\Delta \varepsilon_{\mathrm{p}}\right)^{n}=\frac{\Delta \varepsilon_{\mathrm{p}} \Delta \sigma}{n+1} .
$$

The strain energy of coal sample deformation $(\Delta E)$ is clearly proportional to the difference of stress level $(\Delta \sigma)$.
When the lower stress limit is fixed, $\Delta E$ increases with increasing upper stress limit. Because strain energy stored in coal is released instantaneously in the form of elastic or stress waves, increased strain energy inevitably leads to the gradual increase of AE energy. When using acoustic emission technology to detect the fatigue damage evolution process, what is mainly reflected is the evolution of internal cracks. The characteristics of different deformation stages can be observed from the changing behavior of acoustic emission characterization parameters with time, which allows objective evaluation of coal stability.

Figure 7 shows the variation characteristics of the acoustic emission ringing counting rate, impact counting rate, and energy counting rate of the MB-1 coal sample under different stress levels. In view of the long-time fatigue test of coal under cyclic loading, and the large energy consumption of rock mechanics test system, the number of cyclic loadings under different stress levels in the process of cyclic load test is set to 3000 . In view of the smooth sinusoidal loading waveform and high dynamic stress response, the sinusoidal loading waveform is proposed to be used. In addition, considering the large space of the triaxial chamber of the MTS815.02 electrohydraulic servo rock mechanics test system, if the confining pressure and the loading frequency used in the test are too high, the servo response is poor. According to the test results, the response degree of the confining pressure of $10 \mathrm{MPa}$ and the loading frequency of $0.25 \mathrm{~Hz}$ is better. Therefore, each stress level is loaded 3000 times at $10 \mathrm{MPa}$ with a loading frequency of $0.25 \mathrm{~Hz}$.

The ringing counting rate and impact counting rate mainly reflect the acoustic emission frequency, whereas the energy counting rate mainly reflects the acoustic emission intensity. All three show different behaviors over the full loading process and can be used to evaluate acoustic emission activity from different angles. During the linear loading period to the limit of the first stress level, a small number of primary cracks in coal body are compressed and closed, which leads to the occurrence of acoustic emission phenomena. This indicates that the linear loading process causes initial damage to the samples. Within the first stress level, the acoustic emission is relatively quiet in the initial stage of loading. With increasing loading time, the cracks in the coal body appear periodically closed, the AE signal gradually becomes active, and the coal sample can be considered in a slight fatigue state. Within the second stress level, increasing the upper stress limit increases the rate of initiation, propagation, and accumulation of new cracks in the coal body. More strain energy is released and the active degree of AE signal is more apparent. At this time, the coal sample is in a moderate fatigue state. Within the third stress level, further increase of the upper stress limit causes new cracks to sprout from the coal body and further extend and converge in deeper part. The AE signal is abnormally active with the appearance of the ringing counting rate and energy counting rate. With increasing number of $\mathrm{AE}$ impacts, the accumulated strain energy is more clearly released with additional loading time, and the coal 
TABLE 1: Coal sample size and test conditions.

\begin{tabular}{|c|c|c|c|c|c|c|c|}
\hline \multirow[t]{2}{*}{ Coal samples number } & \multicolumn{3}{|c|}{$\begin{array}{l}\text { Conventional triaxial } \\
\text { compression test }\end{array}$} & \multicolumn{4}{|c|}{ Triaxial cyclic loading test } \\
\hline & MA-1 & MA-2 & MA-3 & MB-1 & MB-2 & MB-3 & MB-4 \\
\hline \multirow{2}{*}{ Coal samples size } & 50.02 & 50.00 & 50.01 & 50.01 & 50.02 & 50.01 & 50.00 \\
\hline & 100.01 & 100.01 & 100.02 & 100.00 & 100.02 & 100.01 & 100.01 \\
\hline Loading frequency $(\mathrm{Hz})$ & - & - & - & 0.25 & 0.5 & 0.25 & 0.5 \\
\hline Confining pressure $(\mathrm{MPa})$ & & 10 & & & & & \\
\hline $\begin{array}{l}\text { Conventional triaxial } \\
\text { compressive strength } \sigma_{\mathrm{c}}(\mathrm{MPa})\end{array}$ & 56.84 & 55.37 & 60.21 & - & - & - & - \\
\hline Average compressive strength $\bar{\sigma}_{\mathrm{c}}(\mathrm{MPa})$ & & 57.47 & & - & - & - & - \\
\hline
\end{tabular}

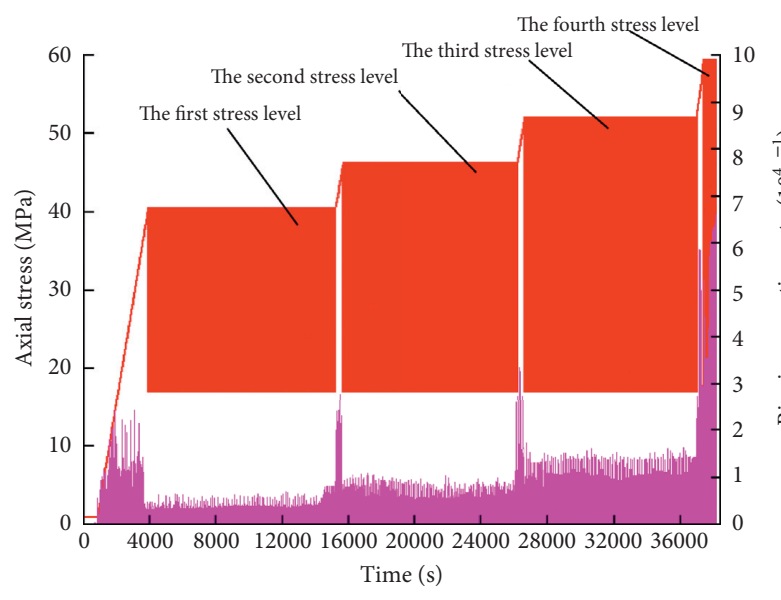

(a)

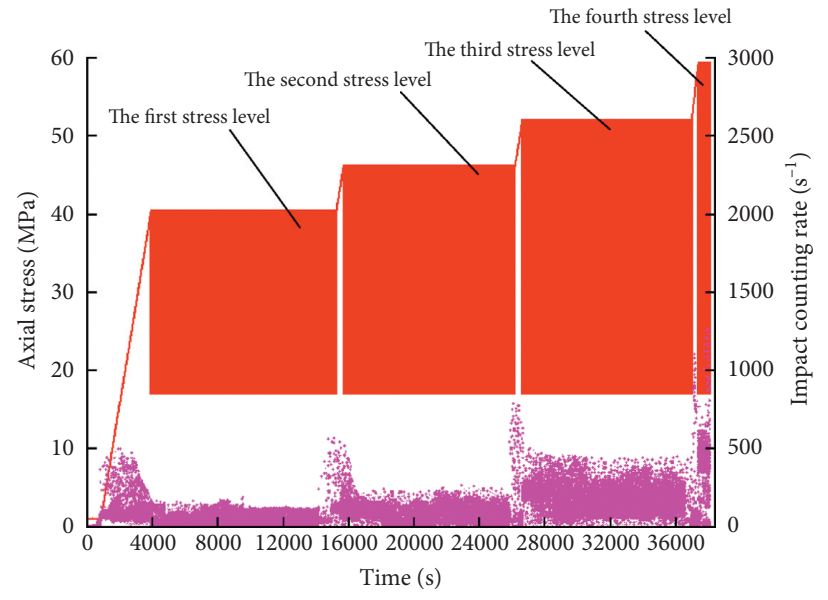

(b)

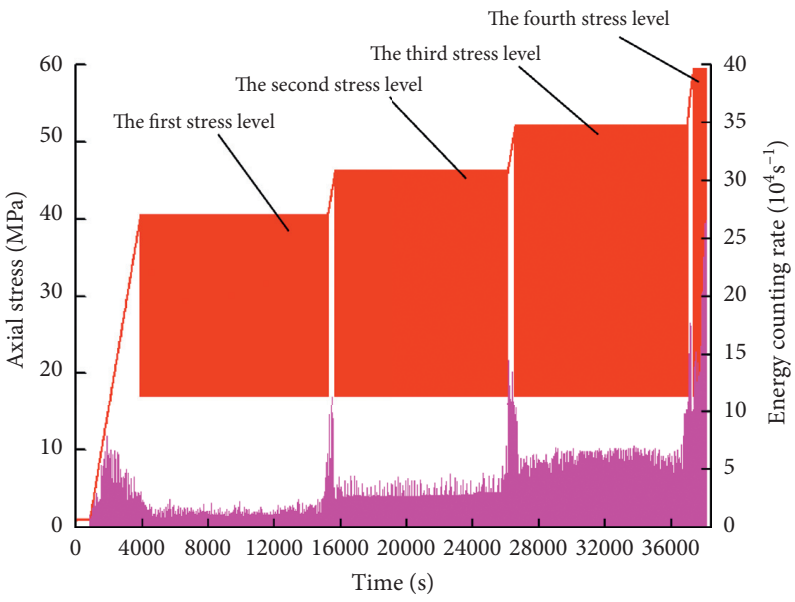

(c)

Figure 7: Acoustic emission characteristics of coal from triaxial tests under cyclic loading and different stress levels. (a) Ringing counting rate, (b) impact counting rate, and (c) energy counting rate.

samples enter the deep fatigue state. Within the fourth stress level, the upper stress limit is close to the average compressive strength of the coal samples under triaxial compression. At this time, the cumulative damage caused by the combination of linear loading and cyclic loading makes the coal sample gradually lose its support capacity, and the internal energy is released completely. Particularly in the dozens of cycles before the failure point, the $\mathrm{AE}$ signal is extremely active, and the ringing counting rate, impact counting, and energy counting all increase sharply. Finally, the fatigue failure of coal samples occurs after 154 loading times.

Compared with other loading tests, this test shows different development and change rules under cyclic loading. The acoustic emission shows the "L-" type development evolution law in any previous stress level range, while at the last stress level, it shows the obvious "U-" type development evolution law. 


\subsection{Effect of Cyclic Loading Frequency on Acoustic Emission} Characteristics. At the same stress level, the effect of loading frequency on acoustic emission is mainly reflected in the change of $\mathrm{AE}$ ringing counting rate. The increase of loading frequency accelerates the damage process of coal, that is to say, increases the rate of initiation and propagation of microcracks and also increases the $\mathrm{AE}$ ringing counting rate. Figures $8(a)$ and $8(b)$ show the distribution characteristics of $\mathrm{AE}$ ring counts of coal samples MB-3 and MB-4 under the same confining pressure (10 MPa), stress level (upper limit stress is $90 \%$ of the average compressive strength of the conventional triaxial), and two different cyclic loading frequencies $(0.25$ and $0.5 \mathrm{~Hz})$, respectively, which are close to the first 20 cycles of fatigue failure. Emphasis is placed on the study of acoustic emission precursory characteristics of coal fatigue failure. As crack propagation under cyclic loading is a process of continuous closure and opening, the increase of cyclic loading frequency causes many cracks to have new energy injection when they are not closed, reducing the resistance needed in the opening process and accelerating crack propagation and energy release, which is reflected in the change of ringing counting rate. As shown in Figures 8(a) and 8(b), the coal samples show distinct characteristics in each cycle of cyclic loading. The counting rates of acoustic emission rings at different loading frequencies under the same confining pressure and stress level also vary substantially. Particularly in the damage stage of the formation and propagation of the main cracks, the counting rates of acoustic emission rings clearly increase with increasing load frequency, which also increases the coal fatigue failure process.

Similarly, Figures 9(a), 9(b), 10(a), and 10(b) show the behavior of the $\mathrm{AE}$ impact counting rate and energy counting rate with time under the same conditions in the 20 cycles prior to fatigue failure of the coal samples. Through comparing and analyzing the graphs, we can see that the $\mathrm{AE}$ rate is higher when the frequency is $0.5 \mathrm{~Hz}$ regardless of ring count, impact count, or energy count. At the same time, variation of the $\mathrm{AE}$ ringing counting rate and energy counting rate is similar, which is consistent with the acoustic emission characteristics of coal under monotonic loading conditions [27]. During the tests, the propagation rate of new cracks differs owing to the different loading frequencies. Higher loading frequencies inevitably lead to faster crack growth rates and the detected $\mathrm{AE}$ energy will also increase. This further illustrates that the fatigue damage process of coal reflects the process of energy release.

\section{Fracture Morphology and Acoustic Emission Felicity Effects of Coal under Triaxial Cyclic Loading}

4.1. Comparative Analysis of Coal Sample Fracture Morphology. Because the fracture morphology of coal samples under the same loading condition is similar, the fracture morphology of coal samples MA-1 and MB-2 under conventional triaxial compression and triaxial cyclic loading was selected to carry out comparative analysis. As shown in
Figure 11, under conventional triaxial compression, shear or splitting failure occurs mainly along the direction of the main fracture surface, while under triaxial cyclic loading, the failure modes are relatively complex. The influence of different stress levels on the initiation and propagation rate of microcracks in the coal samples clearly differs. Initial damage under linear loading and fatigue damage under cyclic loading causes the coal samples to present shear failure modes along multiple fracture surfaces.

4.2. Acoustic Emission Felicity Effect of Coal Samples. The Felicity effect, also known as the anti-Kaiser effect, means that observable acoustic emission occurs before the repetitive load reaches the original maximum load for component materials under repeated loading. This is the memory characteristic of acoustic emission information, which characterizes the irreversibility of acoustic emission. The Felicity ratio is a measure of the failure degree of the Kaiser effect, which reflects the irreversibility of acoustic emission. A Felicity ratio of 1 indicates that the Kaiser effect is valid and the coal rock memory lags behind. As the Felicity ratio approaches 1, this is indicative of higher accuracy of the memory ability of the Kaiser effect. A Felicity ratio of 1 indicates that the Felicity effect is valid and the coal rock memory is ahead of time. The Felicity ratio is a broader description of the irreversibility of the acoustic emission process on the coal. Smaller ratios are associated with more apparent Felicity effects. The Felicity ratio has been well applied in composite materials (e.g., reinforced plastics, aerospace industry materials), but is seldom used in coal materials. The Felicity ratio is often used as an important criterion for evaluating the severity of material defects in engineering and can accurately reflect the degree of original damage or structural defects.

At present, the study of rock memory is mostly based on acoustic emission test results under graded cyclic loading. The common points of these results are that there are more Kaiser effects in rock but lower Felicity effects (i.e., antiKaiser effects), and criteria for determining Felicity effects have not been discussed in previous studies [28-30]. The guideline recommended by the US CARP is to determine the beginning of "obvious" acoustic emission [31]. This shows that when the load increases by $5 \%, \mathrm{AE}$ counts more than 10 events. However, when the load increases by $10 \%, \mathrm{AE}$ counts more than 20 ring counts. In this paper, the Felicity ratio of axial stress $\left(F_{\sigma_{1}}\right)$, principal stress difference $\left(F_{\sigma_{1}-\sigma_{3}}\right)$, volumetric strain $\left(F_{\varepsilon_{V}}\right)$, axial strain $\left(F_{\varepsilon_{1}}\right)$, Poisson's ratio $\left(F_{\mu}\right)$, and elastic modulus $\left(F_{E}\right)$ are used to study the memory characteristics of coal. Among them, $F_{\sigma_{1}}=\left(\sigma_{1 \mathrm{AE}} / \sigma_{1 \mathrm{max}}\right)$, $F_{\sigma_{1}-\sigma_{3}}=\left(\left(\left(\sigma_{1}-\sigma_{3}\right)_{\mathrm{AE}}\right) /\left(\left(\sigma_{1}-\sigma_{3}\right)_{\max }\right)\right), F_{\varepsilon_{V}}=\left(\varepsilon_{V \mathrm{AE}} / \varepsilon_{V \max }\right)$, $F_{\varepsilon_{1}}=\left(\left(\varepsilon_{1 \mathrm{AE}}\right) / \varepsilon_{1 \max }\right), \quad F_{\mu}=\left(\mu_{\mathrm{AE}} / \mu_{\max }\right), \quad F_{E}=\left(E_{\mathrm{AE}} / E_{\max }\right)$, initial $\mathrm{AE}$ axial stress $\left(\sigma_{1 \mathrm{AE}}\right)$, initial principal stress difference $\left(\left(\sigma_{1}-\sigma_{3}\right)_{\mathrm{AE}}\right)$, initial volumetric strain $\left(\varepsilon_{V A \mathrm{E}}\right)$, initial $\mathrm{AE}$ axial strain $\left(\varepsilon_{1 \mathrm{AE}}\right)$, initial Poisson's ratio $\left(\mu_{\mathrm{AE}}\right)$, and initial elastic modulus $\left(F_{E}\right)$ under repeated loading are used. The maximum axial stress $\left(\sigma_{1 \max }\right)$, the maximum principal stress difference $\left(\left(\sigma_{1}-\sigma_{3}\right)_{\max }\right)$, the maximum volume strain $\left(\varepsilon_{V \max }\right)$, the maximum axial strain $\left(\varepsilon_{1 \max }\right)$, the maximum 


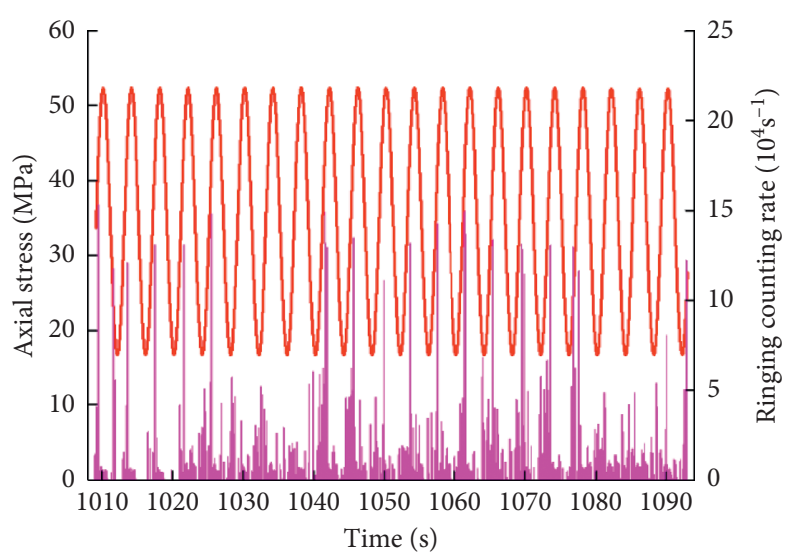

(a)

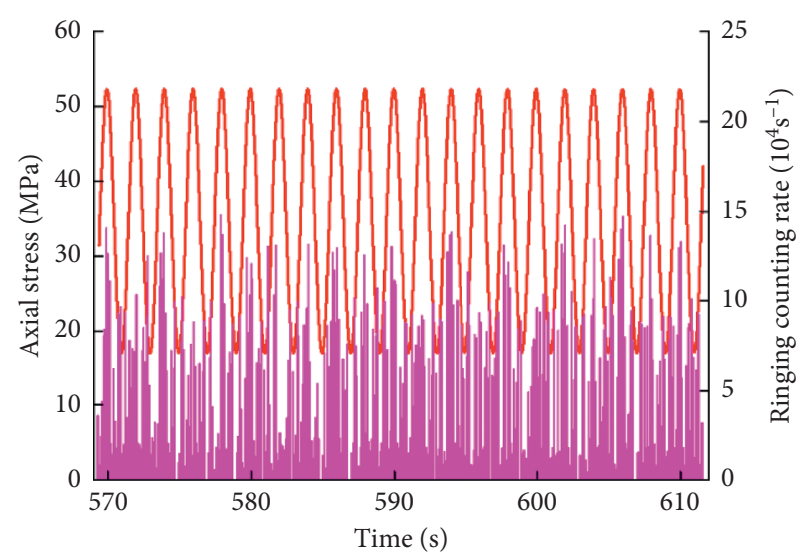

(b)

Figure 8: Acoustic emission ringing counting rate under the same confining pressure and stress level and different cyclic loading frequency. (a) $\mathrm{MB}-3,0.25 \mathrm{~Hz}$ and (b) $\mathrm{MB}-4,0.5 \mathrm{~Hz}$.

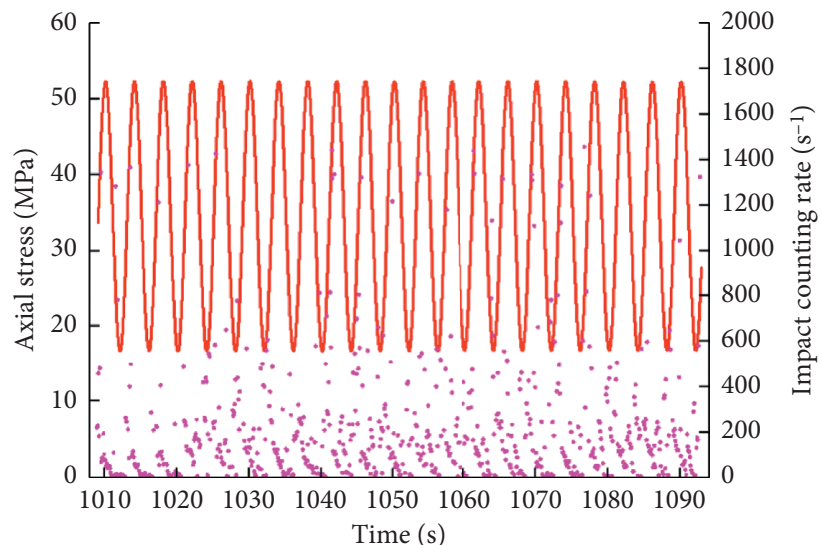

(a)

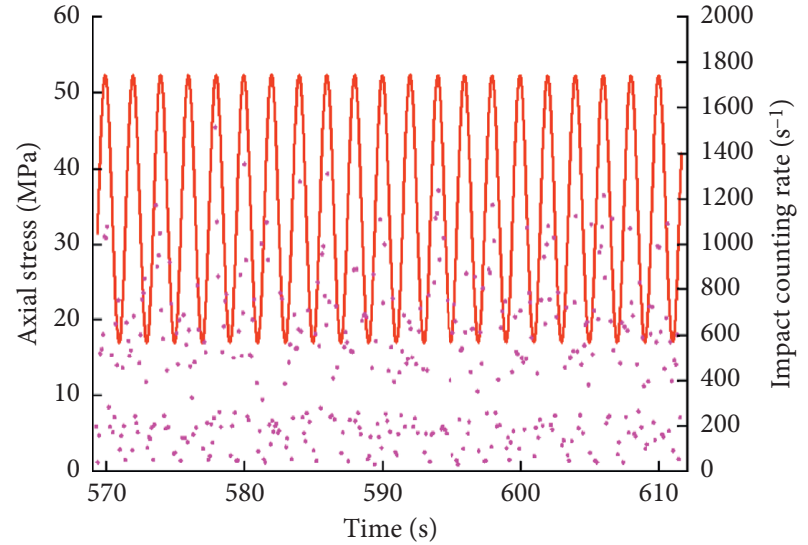

(b)

FIGURE 9: Acoustic emission impact counting rate under the same confining pressure and stress level and different cyclic loading frequency. (a) MB-3, $0.25 \mathrm{~Hz}$ and (b) MB-4, $0.5 \mathrm{~Hz}$.

Poisson ratio $\left(\mu_{\max }\right)$, and the maximum modulus of elasticity $\left(E_{\max }\right)$ depend on the data of the last loading. Table 2 shows the average Felicity ratio of coal samples under different stress levels.

Taking coal sample MB-2 as an example in the range of the first stress level, the Felicity ratio average for each parameter of coal deformation is less than 1, which indicates that there is a Felicity effect in coal under cyclic loading, but it is not very apparent. At this stage, the primary cracks in the coal gradually close, elastic deformation gradually develops, and the memory effect is not apparent. In the range of the second stress level, the ratio of Felicity to the average value of each parameter of coal deformation decreases, which indicates that the Felicity effect gradually increases with increasing upper limit stress. This stage is in the initiation period of microcrack initiation in coal samples, and some new cracks have begun to expand at depth. The coal samples show clear plastic deformation and their memory effect advances. In the range of the third stress level, the ratio of Felicity to the average value is further reduced and the effect of Felicity is clearly enhanced. At this stage, the new cracks initiated in the coal samples begin to substantially propagate until they converge and penetrate and ultimately form fracture surfaces in different directions. In the fourth stress level range, fatigue failure occurs macroscopically. At this time, the new internal cracks converge and penetrate along different fracture plane directions, the degree of damage evolution is clearly deepened, and the Felicity effect is the most apparent.

We observe a clear Felicity effect in coal samples under triaxial cyclic loading and the extent varies substantially over the different stress levels. With increasing the upper limit stress, the Felicity ratio gradually decreases, and the Felicity effect gradually increases. Generally speaking, the average Felicity ratio of elastic modulus shows no observable change, the average Felicity ratio of the Poisson ratio decreases slightly, and the average Felicity ratio of axial strain and volumetric strain varies greatly. In contrast, the average Felicity ratios of axial stress and principal stress difference decrease more significantly, and the latter is more significant than the former. The principal stress difference is therefore a 


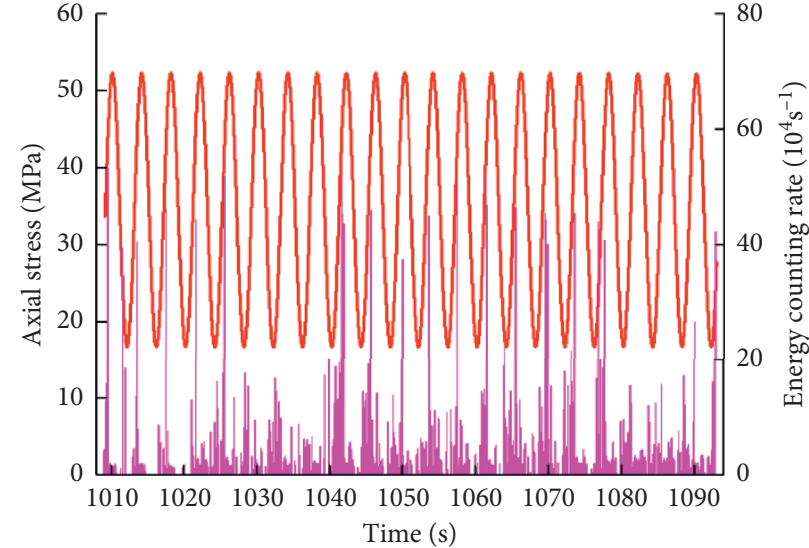

(a)

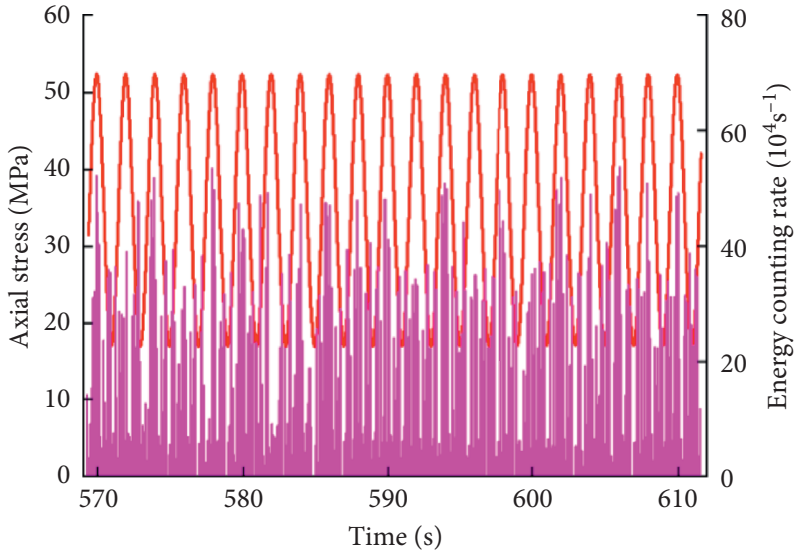

(b)

FIGURE 10: Acoustic emission energy counting rate under the same confining pressure and stress level and different cyclic loading frequency. (a) MB-3, $0.25 \mathrm{~Hz}$ and (b) MB-4, $0.5 \mathrm{~Hz}$.

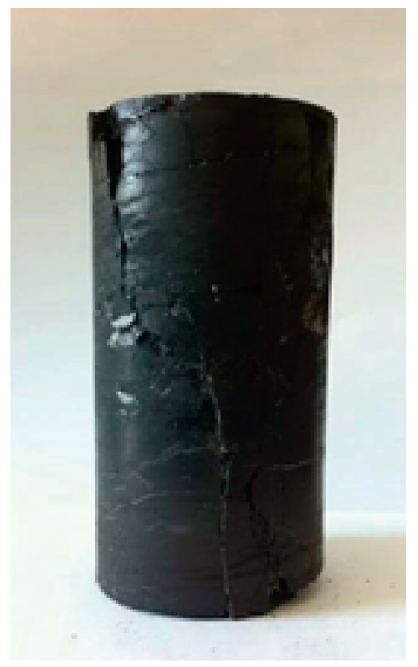

(a)

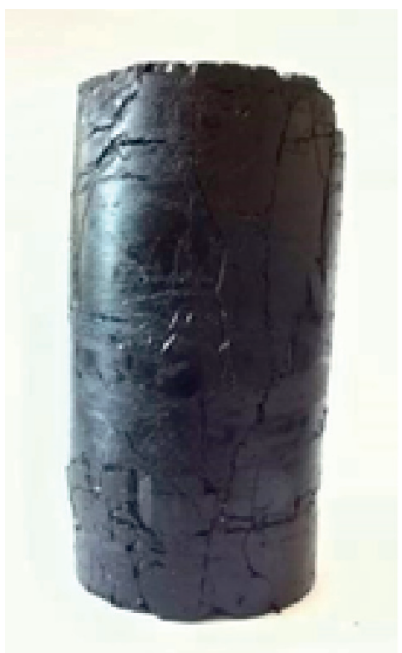

(b)

Figure 11: Fracture morphology of coal samples. (a) MA-1 and (b) MB-2.

Table 2: Average Felicity ratio of coal samples under cyclic loading

\begin{tabular}{|c|c|c|c|c|c|c|c|}
\hline Coal sample number & Stress level & $\bar{F}_{\sigma_{1}}$ & $\bar{F}_{\sigma_{1}-\sigma_{3}}$ & $\bar{F}_{\varepsilon_{V}}$ & $\bar{F}_{\varepsilon_{1}}$ & $\bar{F}_{\mu}$ & $\bar{F}_{E}$ \\
\hline \multirow{4}{*}{ MB-1 } & First & 0.941 & 0.892 & 0.963 & 0.969 & 0.988 & 0.990 \\
\hline & Second & 0.872 & 0.796 & 0.902 & 0.867 & 0.905 & 0.917 \\
\hline & Third & 0.511 & 0.468 & 0.637 & 0.731 & 0.857 & 0.893 \\
\hline & Fourth & 0.308 & 0.203 & 0.402 & 0.419 & 0.795 & 0.809 \\
\hline \multirow{4}{*}{ MB-2 } & First & 0.936 & 0.899 & 0.952 & 0.957 & 0.979 & 0.987 \\
\hline & Second & 0.869 & 0.752 & 0.897 & 0.871 & 0.901 & 0.902 \\
\hline & Third & 0.504 & 0.424 & 0.559 & 0.513 & 0.890 & 0.883 \\
\hline & Fourth & 0.296 & 0.165 & 0.371 & 0.319 & 0.736 & 0.815 \\
\hline \multirow{4}{*}{ MB-3 } & First & 0.945 & 0.837 & 0.956 & 0.978 & 0.981 & 0.995 \\
\hline & Second & 0.867 & 0.710 & 0.899 & 0.886 & 0.902 & 0.912 \\
\hline & Third & 0.519 & 0.401 & 0.637 & 0.533 & 0.895 & 0.894 \\
\hline & Fourth & 0.293 & 0.185 & 0.373 & 0.328 & 0.731 & 0.806 \\
\hline \multirow{4}{*}{ MB-4 } & First & 0.942 & 0.862 & 0.961 & 0.958 & 0.987 & 0.989 \\
\hline & Second & 0.870 & 0.717 & 0.893 & 0.867 & 0.890 & 0.917 \\
\hline & Third & 0.515 & 0.385 & 0.560 & 0.525 & 0.621 & 0.893 \\
\hline & Fourth & 0.301 & 0.192 & 0.372 & 0.419 & 0.598 & 0.818 \\
\hline
\end{tabular}


reasonable parameter to use for studying the Felicity effect of coal.

\section{Conclusions}

(1) Acoustic emissions contain important information about the change of internal structure and fatigue failure of coal. The variation of acoustic emission rates reflects the evolution of coal under triaxial cyclic loading and characteristics during each stage of fatigue damage. The macroscopic appearance and acoustic emission characteristics of coal fatigue failure under cyclic loading show different development behaviors under different stress loading stages

(2) Fatigue tests of coal samples under cyclic loading mainly include the linear loading stage and cyclic loading stage. Under linear loading, the internal coal cracks are gradually compacted, which occurs in the elastic stage of crack compaction and closure, and a small amount of acoustic emission appears. This indicates that the linear loading process in the early stage of cyclic loading still produces some initial damage that enhances the fatigue damage produced in subsequent stages of the cyclic loading

(3) Stress level has an important influence on the acoustic emission characteristics of coal fatigue damage evolution. When the lower limit stress is fixed, higher upper limit stress is associated with more active AE signals. Particularly within the stress level of coal fatigue failure, the AE ringing counting rate and energy counting rate increase sharply and the number of impacts increases significantly. The subsequent stages of fatigue damage occur with increasing loading time: slight fatigue, moderate fatigue, deep fatigue, and ultimate fatigue failure. The acoustic emission shows the "L-" type development evolution law in any previous stress level range, while at the last stress level, it shows the obvious "U-" type development evolution law

(4) At the same stress level and confining pressure, if the frequency of cyclic loading increases, the propagation rate of microcracks also increases, which accelerates coal fatigue damage failure and significantly increases the impact counting, whereas the ringing counting rate and energy counting rate are essentially the same. The dynamic change of acoustic emission reflects the process of primary crack closure, crack initiation, propagation, and convergence in coal samples from side to side

(5) The fatigue failure modes of the coal samples under cyclic loading differ from those under conventional triaxial compression. In conventional triaxial compression tests, shear or splitting failure of coal samples generally occurs along the main fracture surface, whereas under cyclic loading, the coal samples show intricate shear failure along the fracture surface in different directions and is accompanied by Felicity effects in different stress levels. With the continuous increase of stress level, the Felicity effect is gradually enhanced. Compared with axial stress, axial strain, volumetric strain, Poisson's ratio, and elastic modulus, the principal stress difference is more reliable to use to study the AE-Felicity effect of coal.

\section{Data Availability}

The data used to support the findings of this study are included within the article.

\section{Disclosure}

Yongjie Yang and Luyi Xing are co-first authors.

\section{Conflicts of Interest}

The authors declare that there are no conflicts of interest regarding the publication of this paper.

\section{Authors' Contributions}

Yongjie Yang and Luyi Xing authors are contributed equally to this work.

\section{Acknowledgments}

The authors gratefully thank all researchers who participated in the triaxial cyclic loading acoustic emission tests. The authors thank Esther Posner, Ph.D., from Edanz Group (http://www.edanzediting.com/ac) for editing a draft of this manuscript. This work was supported by the National Key R\&D Program of China (Grant no. 2018YFC0604705), the National Natural Science Foundation of China (Grant nos. 51574156 and 51379116), the Doctoral Research Fund of Shandong Jianzhu University (Grant no. XNBS20116), and the Tai'shan Scholar Talent Team Support Plan for Advantaged and Unique Discipline Areas.

\section{References}

[1] C. A. Tang, Catastrophe in Rock Unstable Failure, China Coal Industry Publishing House, Beijing, China, 1993.

[2] W. G. Cao, C. Zhang, M. He, and T. Liu, "Deformation simulation of brittle rock based on micromechanical properties," Rock and Soil Mechanics, vol. 37, no. 10, pp. 27532760, 2016.

[3] H. Kawakata, A. Cho, T. Yanagidani, and M. Shimada, "The observations of faulting in Westerly granite under triaxial compression by X-ray CT scan," International Journal of Rock Mechanics and Mining Sciences, vol. 34, no. 3/4, pp. 151-162, 1997.

[4] W. Li, N. Yang, Y. Mei, Y. Zhang, L. Wang, and H. Ma, "Experimental investigation of the compression-bending property of the casing joints in a concrete filled steel tubular supporting arch for tunnel engineering," Tunnelling and Underground Space Technology, vol. 96, p. 103184, 2020.

[5] J. S. O. Lau and N. A. Chandler, "Innovative laboratory testing," International Journal of Rock Mechanics and Mining Sciences, vol. 41, no. 8, pp. 1427-1445, 2004. 
[6] Y. T. Du, T. C. Li, S. L. Zhang, and L. X. Lü, "Propagation mechanism of $3 \mathrm{D}$ through fracture with different dip angles under uniaxial compression load," Journal of Shandong University of Science and Technology (Natural Science), vol. 35, no. 3, pp. 53-60, 2016.

[7] D. Lockner, "The role of acoustic emission in the study of rock fracture," International Journal of Rock Mechanics and Mining Sciences \& Geomechanics Abstracts, vol. 30, no. 7, pp. 883899, 1993.

[8] S. Q. Qin, Z. D. Li, Z. Y. Zhang, and R. G. Deng, An Introduction to Acoustic Emission Techniques in Rocks, Southwest Jiaotong University Press, Chengdu, China, 1993.

[9] Y. J. Yang, D. C. Wang, M. F. Guo, and B. Li, "Study of rock damage characteristics based on acoustic emission tests under triaxial compression," Chinese Journal of Rock Mechanics and Engineering, vol. 33, no. 1, pp. 98-104, 2014.

[10] I. P. Shcherbakov, V. S. Kuksenko, and A. E. Chmel "Acoustic emission accumulation stage in compression and impact rupture of granite," Journal of Mining Science, vol. 48, no. 4, pp. 656-659, 2012.

[11] Y. C. Zhao, B. Lin, X. Y. Tang, Y. H. Gong, J. Liu, and Y. N. Gao, "Coal Acoustic emission characteristics and damage evolution under uniaxial compression," Journal of Shandong University of Science and Technology (Natural Science), vol. 32, no. 5, pp. 1-7, 2013.

[12] G. Manthei, "Characterization of acoustic emission sources in a rock salt specimen under triaxial compression," Bulletin of the Seismological Society of America, vol. 95, no. 5, pp. 1674-1700, 2005.

[13] K. Mogi, Experimental Rock Mechanics, pp. 263-286, Taylor \& Francis Group, London, UK, 2007.

[14] S. Shahidan, R. Pulin, N. Muhamad Bunnori, and K. M. Holford, "Damage classification in reinforced concrete beam by acoustic emission signal analysis," Construction and Building Materials, vol. 45, no. 13, pp. 78-86, 2013.

[15] H. Nakasa, Availability of Acoustic Emission Amplitude Distribution as Fractal Progress in Acoustic Emission, Japanese Society for Non-Destructive Inspection, Kobe, Japan, 1988.

[16] Y. J. Yang, L. Y. Xing, H. Q. Duan, L. Deng, and Y. C. Xue, "Fatigue damage evolution of coal under cyclic loading," Arabian Journal of Geosciences, vol. 11, no. 18, p. 560, 2018.

[17] Y. J. Yang, D. C. Wang, B. Li, and D. P. Ma, "Acoustic emission characteristics of coal damage failure under triaxial compression," Journal of Basic Science and Engineering, vol. 23, no. 1, pp. 127-135, 2015.

[18] B. X. Liu, J. L. Huang, Z. Y. Wang, and L. Liu, "Study on damage evolution and acoustic emission character of coalrock under uniaxial compression," Chinese Journal of Rock Mechanics and Engineering, vol. 28, no. Supp. 1, pp. 3234$3238,2009$.

[19] H. G. Ji and X. Lu, "Characteristic of acoustic emission and rock fracture precursors of granite under conventional of triaxial compression," Chinese Journal of Rock Mechanics and Engineering, vol. 34, no. 4, pp. 694-702, 2015.

[20] Y. M. Song, T. Z. Xing, T. B. Zhao, Z. X. Zhao, and P. B. Gao, "Acoustic emission characteristics of deformation field development of rock under uniaxial loading," Chinese Journal of Rock Mechanics and Engineering, vol. 36, no. 3, pp. 534-542, 2017.

[21] J. P. Zou, W. Z. Chen, D. S. Yang, J. Q. Yuan, and X. J. Tan, "Mechanical properties and damage evolution of coal under cyclic loading conditions," Journal of China Coal Society, vol. 41, no. 7, pp. 1675-1682, 2016.
[22] F. K. Xiao, G. Liu, Z. L. Shen, F. R. Zhang, and Y. F. Wang, "Energy conversion and acoustic emission (AE) characteristics of coal samples under cyclic loading," Chinese Journal of Rock Mechanics and Engineering, vol. 35, no. 11, pp. 19541964, 2016.

[23] H. H. Zhang, F. Liu, and F. Q. Chang, "Experimental study of acoustic emission characteristics during rock failure process and energy properties," Journal of Highway and Transportation Research and Development, vol. 28, no. 3, pp. 48-54, 2011.

[24] X. Kong, E. Wang, X. He, E. Zhao, and C. Zhao, "Mechanical characteristics and dynamic damage evolution mechanism of coal samples in compressive loading experiments," Engineering Fracture Mechanics, vol. 210, pp. 160-169, 2019.

[25] X. G. Kong, E. Y. Wang, S. G. Li, H. F. Lin, P. Xiao, and K. Z. Zhang, "Fractals and chaos characteristics of acoustic emission energy about gas-bearing coal during loaded failure," Fractals, vol. 27, no. 5, Article ID 1950072, 2019.

[26] B. Kong, E. Wang, W. Lu, and Z. Li, "Application of electromagnetic radiation detection in high-temperature anomalous areas experiencing coalfield fires," Energy, vol. 189, Article ID 116144, 2019.

[27] Y. J. Yang, S. J. Chen, and G. D. Han, "Experimental on acoustic emission during compression rupture procedure of coal sample," Journal of China Coal Society, vol. 31, no. 5, pp. 562-565, 2006.

[28] Y. L. Chen, Z. A. Wei, and Q. G. Zhang, "Experimental study on Felicity effect of acoustic emission in rock under cyclic loading and tiered cyclic loading," Journal of China Coal Society, vol. 37, no. 2, pp. 226-230, 2012.

[29] E. J. Kaiser, A Study of Acoustic Phenomena in Tensile Test, Ph. D. thesis, Technische Hochschule Munchen, Munich, Germany, 1953.

[30] X. J. Tang, B. Yan, and J. Xu, "Felicity effect of sandstone under cycling loading conditions," Soil Engineering and Foundation, vol. 25, no. 4, pp. 103-106, 2015.

[31] M. W. Yang, Acoustic Emission Testing, China Machine Press, Beijing, China, 2005. 